\title{
Heat shock protein 70 mRNA expression and immune response of heat-stressed finishing broilers fed propolis (bee glue) supplementation
}

\author{
S. M. Hosseini ${ }^{1}$, M. Afshar ${ }^{1}$, S. Ahani ${ }^{2}$, and M. Vakili Azghandi ${ }^{3}$ \\ ${ }^{1}$ Department of Animal Science, Faculty of Agriculture, University of Birjand, Birjand, Iran \\ ${ }^{2}$ Department of Animal Science, Kashmar Branch, Islamic Azad University, Kashmar, Iran \\ ${ }^{3}$ Young Researchers and Elites Club, Birjand Branch, Islamic Azad University, Birjand, Iran
}

Correspondence to: M. Vakili Azghandi (m.vakili2009@gmail.com)

\begin{abstract}
Received: 13 August 2015 - Revised: 26 October 2015 - Accepted: 3 November 2015 - Published: 11 November 2015
\end{abstract}
\begin{abstract}
This $2 \times 2$ factorial experiment investigated the efficacy of propolis (bee glue; BG) in ameliorating heat-stress-induced impairment of growth performance, the hematological profile, intestinal morphology, and biomarkers of heat stress in broilers. Two hundred and forty 21-day old Ross 308 male broiler chicks were allocated to four experimental treatments in six replicates of 10 birds each. The main factors were composed of diet (basal diet or addition of $3 \mathrm{~g} \mathrm{~kg}^{-1}$ of BG) and temperature (thermoneutral or heat stress). Broilers subjected to heat stress had reduced average daily gain (ADG) and average daily feed intake (ADFI); a higher heterophil level and heterophil-to-lymphocyte ratio, and a lower lymphocyte level; upregulated mRNA expression of $70 \mathrm{kDa}$ heat shock protein (HSP70) levels in heart, kidney, and breast muscle; and shorter jejunal villus height, deeper crypt depth, and a lower ratio of villus-height-to-crypt-depth compared with those broilers raised in thermoneutral conditions. Supplemental BG increased ADG, jejunal villus height, and the villus-height-to-crypt-depth ratio and decreased the feed-to-gain ratio and creatine kinase and lactate dehydrogenase levels in breast muscle compared with the birds who received control diets. The inclusion of BG in diets significantly decreased the mRNA expression of HSP70 levels in heart, kidney, and breast muscle in birds subjected to heat challenge. These results indicate that the BG-supplemented diet was effective in partially ameliorating adverse effects in resistance to heat stress in broiler chickens.
\end{abstract}

Heat stress (HS) is a critical problem in poultry production systems and has a negative effect on bird health and productivity. High ambient temperatures not only cause heavy economic losses to the poultry industry through reduced feed intake and an increased mortality rate but also result in inferior meat quality (Chiang et al., 2008). It has been shown clearly that exposing broilers to continuously high ambient temperatures, especially during the finisher phase, leads to chronic HS followed by decreased productive performance (Ahmad et al., 2006). Also, HS has been associated with an increased number of heterophils and a decreased number of lymphocytes. In addition, HS increases heat shock proteins expression in skeletal and cardiac muscles, which may en- hance the tolerance to stress and increase the survival rate of the stressed cells (Kamboh et al., 2013). Heat shock proteins are a family of proteins produced in all cells and tissues in response to the exposure to stressful conditions, such as HS (Yahav et al., 1997). The most important of these with respect to HS is heat shock protein $70 \mathrm{kDa}$ (HSP70) (Kamboh et al., 2013).

The dietary application of natural antioxidants is considered an appropriate practical strategy to reduce the deleterious consequences of HS in birds (Seven, 2008). Bee glue (BG, propolis) is a resinous and balsamic material collected by honey bees (Apis mellifera L.) from different tree buds, sap flows, or other botanical sources mixed with their wax and salivary enzymes. Different constituents have been identified in BG samples, such as flavonoids, aromatic acids, caf- 
feic acid, terpenes, and phenolic. It seems that the presence of these important compounds is responsible for the biological and pharmacological properties of BG samples (Banskota et al., 2000). In recent years, attention has been focused on the use of propolis as a health supplement suited to consumers in developed countries (Bankova, 2005). It has strong antioxidant, anti-inflammatory, antifungal, and immunostimulatory properties (and cytostatic and hepatoprotective properties; Banskota et al., 2000). The strong antioxidant BG has been reported to improve productive performance and egg production in laying hens reared under acute HS (Seven, 2008).

No information is available concerning the potential effects of BG in heat-challenged broilers. Therefore, the aim of the current research was to investigate the effect of dietary $\mathrm{BG}$ on growth performance, certain hematological parameters, creatine kinase (CK) and lactate dehydrogenase (LDH) levels in breast muscle, and sHSP70 mRNA expression in liver, heart, kidney, and breast muscle in broilers reared under hot conditions.

\section{Materials and methods}

\subsection{Diets and birds}

Two hundred and forty 21-day-old Ross 308 male broiler chicks were randomly assigned to four treatments with six replicates of 10 birds each. The experiment was designed according to a $2 \times 2$ factorial arrangement of treatments, and the main factors were temperature (thermoneutral or heat stress) and diet (basal diet or diet supplemented with $3 \mathrm{~g} \mathrm{~kg}^{-1}$ of BG). Basal diets were formulated to meet or exceed Ross 308 broiler nutrition specifications for macro- and micronutrients (Table 1; NRC, 1994). The thermoneutral and heatstressed treatments were divided into two separated rooms. Each room was controlled at a given temperature. Before commencing the experiment on day 22, all broilers were reared under the same environmental conditions and provided with the same diet. In the experiment period (2242 days of age), birds were either kept in thermoneutral conditions $\left(22^{\circ} \mathrm{C}\right)$ or subjected to cyclic heat stress by exposing them to $33^{\circ} \mathrm{C}$ for $10 \mathrm{~h}$, from 07:00 to 17:00 h (GMT + 3:30), and to $22^{\circ} \mathrm{C}$ from 17:00 to 07:00 $\mathrm{h}$. The lighting program was 23L:1D during the entire period. Air humidity in both temperature treatments was kept at $70 \%$ during the experimental period. The birds were reared in floor pens $(90 \times 120 \times 70 \mathrm{~cm}$, length $\times$ width $\times$ height) and given ad libitum access to feed and water. The animal care protocol in this experiment was approved by the Animal Ethics Committee of the Birjand University.

\subsection{Preparation of $B G$}

The BG was mainly collected by the honey bee from Amygdalus scoparia L. in the spring season. Thirty grams of BG was extracted with $100 \mathrm{~mL}$ of $70 \%$ ethanol, in the absence of
Table 1. Ingredients and calculated and analysed compositions of the basal diet.

\begin{tabular}{|c|c|}
\hline & Amount \\
\hline \multicolumn{2}{|l|}{ Ingredients $(\%)$} \\
\hline Corn ( $8 \%$ crude protein) & 56.20 \\
\hline Soybean meal ( $48 \%$ crude protein) & 36.06 \\
\hline Corn oil & 4.00 \\
\hline Limestone & 1.12 \\
\hline Dicalcium phosphate & 1.45 \\
\hline Calcium carbonate & 0.57 \\
\hline Salt & 0.45 \\
\hline L-Lysine & 0.10 \\
\hline DL-Methionine & 0.12 \\
\hline Vitamin-mineral premix* & 0.50 \\
\hline \multicolumn{2}{|l|}{ Calculated composition } \\
\hline Metabolizable energy $\left(\mathrm{MJ} \mathrm{kg}^{-1}\right)$ & 13.4 \\
\hline Available phosphorus $\left(\mathrm{g} \mathrm{kg}^{-1}\right)$ & 4.3 \\
\hline Lysine $\left(\mathrm{g} \mathrm{kg}^{-1}\right)$ & 10.5 \\
\hline Methionine (\%) & 4.0 \\
\hline Methionine + cystine $(\%)$ & 8.0 \\
\hline \multicolumn{2}{|l|}{ Analysed composition $\left(\mathrm{g} \mathrm{kg}^{-1}\right)$} \\
\hline Crude protein $(\mathrm{N} \times 6.25)$ & 201 \\
\hline Crude fat & 68.4 \\
\hline Calcium & 9.1 \\
\hline Total phosphorus & 6.9 \\
\hline Crude fibre & 51.8 \\
\hline \multicolumn{2}{|c|}{$\begin{array}{l}\text { * Vitamin and mineral premix supplied the following per } \\
\text { kilogram of diet: vitamin A (from vitamin A acetate), } 10000 \mathrm{IU} \text {; } \\
\text { vitamin } \mathrm{D}_{3}, 9790 \mathrm{IU} \text {; vitamin } \mathrm{E} \text { (dl- } \alpha \text {-tocopheryl acetate), } \\
30 \mathrm{IU} \text {; vitamin } \mathrm{B}_{12}, 20 \mu \mathrm{g} \text {; riboflavin, } 4.4 \mathrm{mg} \text {; calcium } \\
\text { pantothenate, } 40 \mathrm{mg} \text {; niacin, } 22 \mathrm{mg} \text {; choline, } 840 \mathrm{mg} \text {; biotin, } \\
30 \mu \mathrm{g} \text {; thiamin, } 4 \mathrm{mg} \text {; zinc sulfate, } 60 \mathrm{mg} \text {; copper sulfate, } 100 \mu \mathrm{g} \text {; } \\
\text { selenium (sodium selenate), } 0.2 \mathrm{mg} \text {; iodine, } 1 \mathrm{mg} \text {; manganese } \\
\text { oxide, } 60 \mathrm{mg} \text {. }\end{array}$} \\
\hline
\end{tabular}

bright light, at room temperature. After filtration, the extract was evaporated with a vacuum evaporator at $50{ }^{\circ} \mathrm{C}$.

\subsection{Bird performance}

Body weight was measured at the age of 22 and 42 days and feed intake was measured daily. Average daily gain (ADG), average daily feed intake (ADFI), and the feed conversion ratio (FCR) were calculated for the entire experimental period (22-42 days of age).

\subsection{Hematological analyses}

On day 42, 12 birds per treatment were selected and slaughtered by severing the carotid arteries and jugular veins. Blood samples were collected in tubes containing anticoagulant heparin and kept on ice until arrival at the laboratory where they were used for hematological analysis. Hematological analysis was conducted to measure the levels of lymphocytes and heterophils using an automatic hema- 
Table 2. Effect of propolis (bee glue; BG) on growth performance of broiler chickens subjected to heat challenge $(n=6)$. SEM stands for "standard error of the mean".

\begin{tabular}{lrrr}
\hline Item & ADG $(\mathrm{g})$ & ADFI $(\mathrm{g})$ & FCR $\left(\mathrm{g} \mathrm{g}^{-1}\right)$ \\
\hline Temperature & & & \\
\hline Thermoneutral & $78.1^{\mathrm{a}}$ & $158^{\mathrm{a}}$ & 2.02 \\
Heat stress & $70.2^{\mathrm{b}}$ & $145^{\mathrm{b}}$ & 2.06 \\
\hline Diet & & & \\
\hline Control & $72.5^{\mathrm{b}}$ & 153 & $2.11^{\mathrm{a}}$ \\
BG & $77.0^{\mathrm{a}}$ & 155 & $2.01^{\mathrm{b}}$ \\
SEM & 1.6 & 2 & 0.03 \\
\hline$P$ value & & & \\
\hline Temperature & 0.004 & 0.005 & 0.085 \\
Diet & 0.028 & 0.423 & 0.007 \\
Temperature $\times$ diet & 0.503 & 0.347 & 0.245 \\
\hline
\end{tabular}

a-b Mean values within a column with different letters differ significantly $(P<0.05)$. ADG: average daily gain; ADFI: average daily feed intake; FCR: feed conversion ratio.

tological analyser (XE-2100, Automated Hematology Analyzer, Sysmex America, Inc.). Values of lymphocytes and heterophils counts were also used to calculate the heterophilto-lymphocyte $(\mathrm{H}: \mathrm{L})$ ratio index.

\subsection{Intestinal morphology}

Using the birds killed on day 42, jejunal segments were harvested rapidly. The specimens of mid-jejunum were embedded in paraffin, sectioned $(5 \mu \mathrm{m})$, and stained with hematoxylin-eosin according to the procedures used by $\mathrm{Hu}$ et al. (2013). The morphological measurement of villus height and crypt depth was conducted using an image processing and analysis system (Leica Imaging Systems Ltd., Cambridge,UK). The ratio of villus height to crypt depth was calculated.

\subsection{Analyses of heat stress biomarkers}

The breast (pectoralis major) without skin and adipose tissue was also collected and snap-frozen in liquid nitrogen that was further used to analyse the biomarkers of heat stress including $\mathrm{CK}$ and $\mathrm{LDH}$. These were analysed by using the commercially available kits (Nanjing Jiancheng Bioengineering Institute, Nanjing, China). All protocols were adapted according to manufacturer's instructions.

Quantitative real-time polymerase chain reaction (PCR) was performed to determine the levels of inducible HSP70 mRNA in different tissues. Samples from heart, liver, kidney, and breast were minced and homogenized. The chicken HSP70 gene sequence deposited in GenBank under the accession number J02579 was used as nucleotide sequence in the current research.

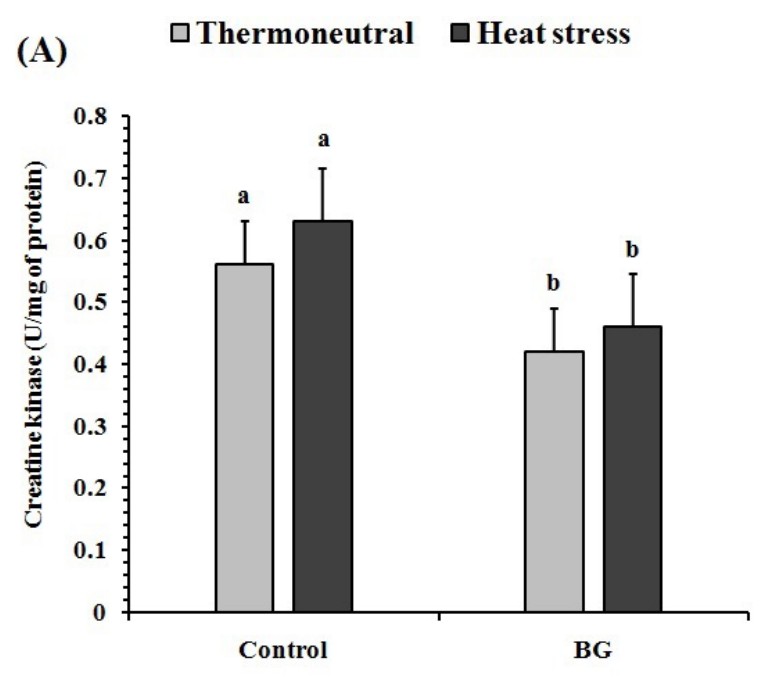

(B)

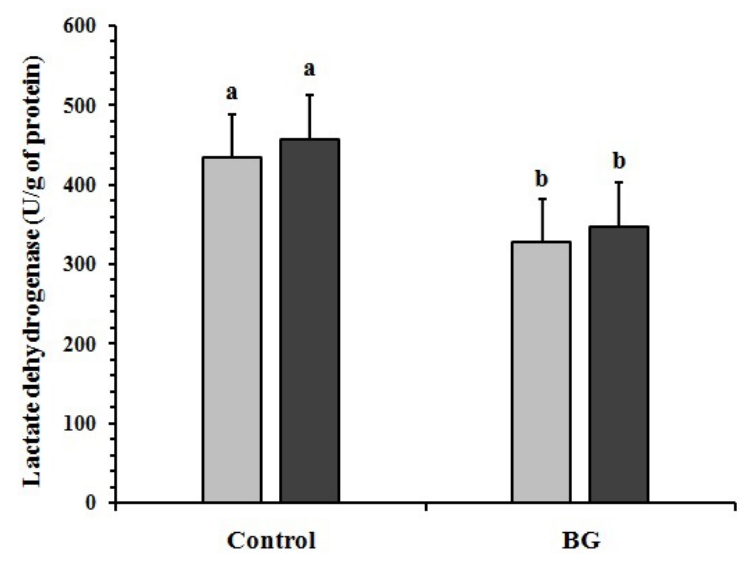

Figure 1. Effect of bee glue (BG) supplementation on (a) creatine kinase (expressed as $\mathrm{U} \mathrm{mg}^{-1}$ of protein) and (b) lactate dehydrogenase (expressed as $\mathrm{U} \mathrm{mg}^{-1}$ of protein) levels in chicken breast muscle. Mean values represent the average of six replicates of four groups $(n=6)$. Values are means \pm SEM. Within the graph, bars with different letters $(\mathrm{a}, \mathrm{b})$ are significantly different $(P<0.05)$.

\subsection{Statistical analyses}

Statistical analyses were performed using SAS (SAS, 2006). Data on productive performance, gut and hematological parameters, and biomarkers were analysed by ANOVA using the general linear model (GLM) procedure appropriate for a factorial arrangement of treatments in a randomized complete design. The statistical model included the effects of temperature (thermoneutral or heat stress), diet (basal diet or supplementation with BG), and their interactions. The corresponding means were compared by Tukey-Kramer's test, and statistical differences were declared to be $P<0.05$. 


\section{$\square$ Thermoneutral $\square$ Heat stress}

(A)

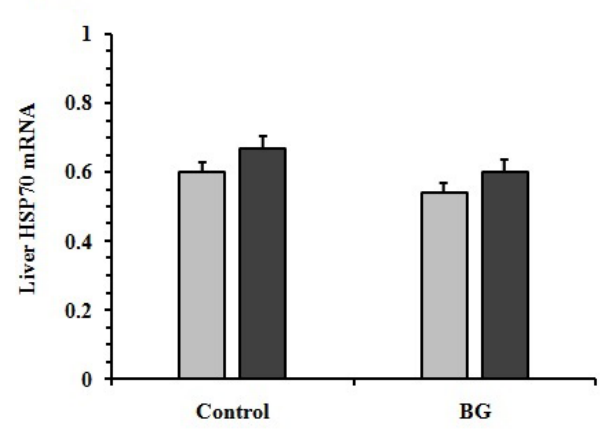

(C)

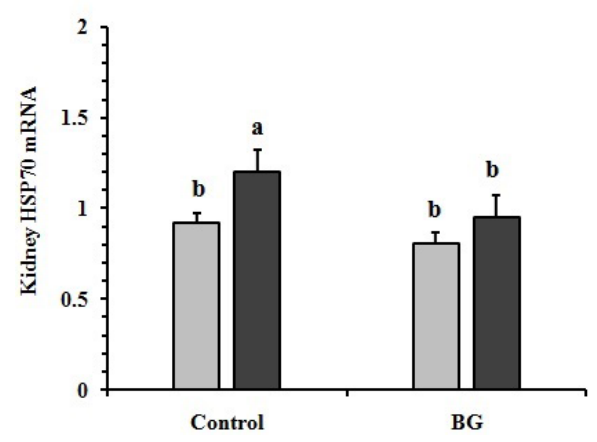

(B)

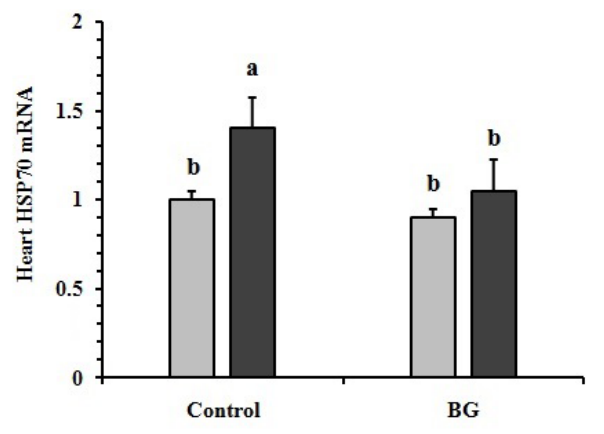

(D)

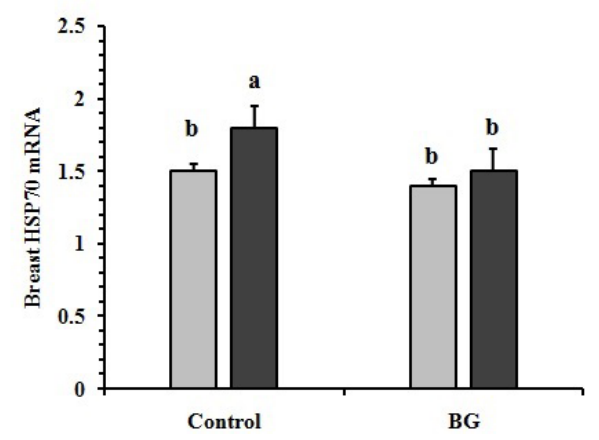

Figure 2. Effect of bee glue (BG) supplementation on gene expression of heat shock protein 70 (HSP70) in liver (a), heart (b), kidney (c), and breast muscle (d) of broilers subjected to heat challenge. Mean values represent the average of six replicates of four groups $(n=6)$. Values are means \pm SEM. Within the graph, bars with different letters $(\mathrm{a}-\mathrm{b})$ are significantly different $(P<0.05)$.

\section{Results}

Broilers with HS had lower ADG $(P=0.004)$ and ADFI $(P=0.005)$ than those in thermoneutral conditions. Relative to broilers fed the basal diet, broilers supplemented with BG had higher ADG $(P=0.028)$ and a lower FCR $(P=0.007)$. Mortality data were not subjected to statistical analysis because just one case of mortality in the control treatment was observed throughout the study (Table 2). No temperature $\times$ diet interaction was observed for the growth performance of broilers.

Compared to the broilers in the thermoneutral zone, heat-stressed broilers had a lower $(P=0.008)$ lymphocyte level and a higher heterophil concentration $(P=0.012)$ and heterophil-to-lymphocyte ratio $(P=0.002$; Table 3). As compared with basal diet, the inclusion of $\mathrm{BG}$ decreased the heterophil-to-lymphocyte ratio $(P=0.025)$. A temperature $\times$ diet interaction was observed for the heterophil-tolymphocyte ratio of broilers $(P=0.046)$.

Bee-glue-supplemented diet significantly decreased $(P<$ 0.05 ) the CK activity in breast muscle (Fig. 1a) in comparison with the basal diet. LDH activity was significantly
$(P<0.01)$ decreased by the dietary BG in comparison with the basal diet (Fig. 1b). No temperature $\times$ diet interaction was observed for CK and LDH levels.

The relative values for HSP70 mRNA expression in heart, liver, kidney, and breast muscle are presented in Fig. 2. Real-time PCR analysis showed that dietary BG downregulated the HSP70 gene expression in heart (Fig. 2b), kidney (Fig. 2c), and breast muscle (Fig. 2c) of the heatchallenged broilers. Compared with broilers in the thermoneutral zone, mRNA levels of HSP70 were increased in heart, kidney, and breast by heat challenge.

Broilers in HS had a shorter $(P<0.001)$ villus height, deeper $(P=0.014)$ crypt depth, and a lower $(P<0.001)$ villus-height-to-crypt-depth ratio than those raised in the thermoneutral zone (Table 4). Broilers fed BG had a greater villus height $(P=0.002)$ and a higher villus-height-to-cryptdepth ratio $(P=0.021)$ than those fed with the basal diet. No temperature $x$ diet interaction was observed for crypt depth and the villus-height-to-crypt-depth ratio in broiler chickens. 
Table 3. Effect of propolis (bee glue; BG) on heterophil and lymphocyte concentrations and the heterophil to lymphocyte $(\mathrm{H}: \mathrm{L})$ ratio of broiler chickens subjected to heat challenge $(n=6)$.

\begin{tabular}{lrrr}
\hline & $\begin{array}{r}\text { Heterophils } \\
\left(\mathrm{H} ; \times 10^{9} / \mathrm{L}\right)\end{array}$ & $\begin{array}{r}\text { Lymphocytes } \\
\left(\mathrm{L} ; \times 10^{9} / \mathrm{L}\right)\end{array}$ & $\begin{array}{r}\mathrm{H}: \mathrm{L} \\
\text { ratio }\end{array}$ \\
\hline Temperature & & & \\
\hline Thermoneutral & $34.2^{\mathrm{b}}$ & $105.4^{\mathrm{a}}$ & $0.32^{\mathrm{b}}$ \\
Heat stress & $36.1^{\mathrm{a}}$ & $101.6^{\mathrm{b}}$ & $0.35^{\mathrm{a}}$ \\
\hline Diet & & & \\
\hline Control & 34.7 & 104.6 & $0.33^{\mathrm{a}}$ \\
BG & 33.4 & 106.5 & $0.31^{\mathrm{b}}$ \\
SEM & 0.4 & 1.2 & 0.03 \\
\hline$P$ value & & & \\
\hline Temperature & 0.012 & 0.008 & 0.002 \\
Diet & 0.285 & 0.137 & 0.025 \\
Temperature $\times$ diet & 0.442 & 0.151 & 0.046 \\
\hline a-b Mean values within a column with different letters differ significantly \\
$(P<0.05)$.
\end{tabular}

Table 4. Effect of propolis (bee glue; BG) on the morphology of the jejunum of broiler chickens subjected to heat challenge $(n=6)$.

\begin{tabular}{lccc}
\hline & $\begin{array}{c}\text { Villus height } \\
(\mu \mathrm{m})\end{array}$ & $\begin{array}{c}\text { Crypt depth } \\
(\mu \mathrm{m})\end{array}$ & Ratio \\
\hline Temperature & & & \\
\hline Thermoneutral & $878^{\mathrm{a}}$ & $204^{\mathrm{b}}$ & $4.30^{\mathrm{a}}$ \\
Heat stress & $741^{\mathrm{b}}$ & $225^{\mathrm{a}}$ & $3.29^{\mathrm{b}}$ \\
\hline Diet & & \\
\hline Control & $752^{\mathrm{b}}$ & 217 & $3.46^{\mathrm{b}}$ \\
BG & $840^{\mathrm{a}}$ & 204 & $4.12^{\mathrm{a}}$ \\
SEM & 24 & 8 & 0.13 \\
\hline$P$ value & \multicolumn{2}{c}{} \\
\hline Temperature & $<0.001$ & 0.014 & $<0.001$ \\
Diet & 0.002 & 0.087 & 0.021 \\
Temperature $\times$ diet & 0.065 & 0.428 & 0.097 \\
\hline a-b Mean values within a column with different letters differ significantly \\
$(P<0.05)$.
\end{tabular}

\section{Discussion}

Heat stress usually as a profound effect on overall animal health and productive performance. Previous reports indicated that HS has negative effects on growth rate and feed intake in broilers (Quinteiro-Filho et al., 2010). In agreement with recent reports (Quinteiro-Filho et al., 2012; Sohail et al., 2012), the results of the current study revealed that HS decreased ADG and ADFI. In heat-challenged birds, more energy is expanded to adapt to the stress conditions; there- fore, less energy was used for growth, leading to a decreased growth performance. On the other hand, the deteriorated performance of heat-stressed broilers can be related to a poor appetite and lowered feed intake, which is a defence mechanism designed to reduce heat build-up in the body. This study indicated that dietary inclusion of BG improved ADG and FCR compared to the basal diet in stressed birds. These findings confirm those reported by Attia et al. (2011), who indicated that BG can be used in poultry feeds as a natural growth promoter. This effect BG may be due to strong action and the presence of micronutrients with positive effects on bird metabolism (Viuda-Martos et al., 2008).

Heat-challenged broilers show increased heterophil and decreased lymphocyte counts which leads to an increase in the $\mathrm{H}: \mathrm{L}$ ratio. The $\mathrm{H}: \mathrm{L}$ ratio is a good quantitative measure of stress. In the thermoneutral room, the $\mathrm{H}: \mathrm{L}$ ratio for the BG treatment was significantly lower than the value obtained for the control treatment. Reports on the effect of BG on the hematological profile are very scarce. It is well recognized that the heterophil-to-lymphocyte $(\mathrm{H}: \mathrm{L})$ ratio is a reliable stress index in birds, and it is known to increase due to the effect of long-term ambient stress including HS (Vleck et al., 2000). Our results regarding the $\mathrm{H}: \mathrm{L}$ ratio in the current study revealed that dietary BG improved tolerance to the permanent HS challenge. Moreover, the decrease in the heterophil count is also a positive index of improving action of dietary antioxidants against HS, as indicated in the current study. In general, the immunological activities observed in the present research indicate that dietary BG can alleviate the negative effects of HS in broilers.

The results of the study indicated that the levels of CK and LDH in breast muscles of broilers were decreased, which is probably an indication of the improving effects of BG supplementation with regard to heat stress challenge. These results agree with study of Patra et al. (2011), who concluded that dietary natural antioxidants are the best strategy against the negative consequences of HS in broiler meat. Hence, the results may suggest that the inclusion of BG could play an important role in the reduction of myopathy in broilers that is indicated by the reduced activities of CK and LDH in breast muscle.

An interesting finding in the present study was the effect of BG supplementation on the HSP70 level in heart, kidney, and breast tissue. The most important reason for measuring the HSP70 in different studies is the evidence that indicate its role not only at high ambient temperatures but also in cell death mediated by free radicals and reactive oxygen species (Jacquier-Sarlin et al., 1994). There is good evidence that high ambient temperatures can induce HSP70 mRNA synthesis through increasing either the amount or the activity of the heat shock transcription factor and consequently the HSP70 level (Craig and Gross, 1991). Higher levels of HSP70 in different tissues of birds after exposure to environmental stressors such as HS have been reported (Craig and Gross, 1991). In the current study, the down-regulation of HSP70 mRNA 
by the dietary BG may be due to a functional likeness of BG with estrogen. This novel finding suggests that an unknown constituent in BG may cause a similar effect to that observed for estrogen on HSP70 induction through a nutritional mechanism. Bongiovanni et al. (2007) investigated the effects of natural antioxidants on stressors including HS and concluded that the dietary inclusion of flavonoids may afford protection against acute HS. Nevertheless, further studies are necessary to investigate the effects of the flavonoids on the down-regulation of HSP70 mRNA and their antioxidant effect in broilers reared under HS.

In the present study, obvious alterations in villus-crypt structure were observed in heat-challenged broilers, which are consistent with the findings of Sohail et al. (2012), who reported decreased villus length in birds subjected to chronic heat stress. Several possible reasons exist as to why intestinal morphology was changed in response to HS, including lesions induced by intestinal ischemia and the presence of toxins (Xu et al., 2009). Ischemia of the enteric canal can cause epithelial shedding (Rivera et al., 2011), proceeding to shortened villus height and deeper crypt depth. Jia et al. (2010) found that both villus height and crypt depth are important indicators of the digestive health of poultry and are directly related to the absorptive capacity of the mucous membrane. In addition, higher villus-to-crypt ratios suggest higher digestive and absorptive capacities in the jejunum (Xu et al., 2009). Thus, the increased ratios obtained in the current study can be attributed to the beneficial effect of the BG on controlling the proliferation of pathogenic bacteria and avoiding possible damage to the intestinal mucosa. Hence, the inclusion of BG in the diet stimulated the digestive and absorptive functions of broilers and may help to explain the improvement in ADG.

\section{Conclusions}

In conclusion, it is clear that HS caused poor production performance in broilers. The birds exposed to HS had an injured jejunal morphology and an increase in the biomarkers of HS than those kept under the thermoneutral conditions. The inclusion of BG in diet improved ADG, FCR, and the morphometric indices of jejunum. The circulating $\mathrm{H}: \mathrm{L}$ ratio, $\mathrm{CK}$, and LDH levels in breast muscle and HSP70 mRNA levels in heart, kidney, and breast were modulated by BG diet supplementation. These results revealed the protective effects of BG against heat challenge in broilers. The implementation of BG as a feed additive may offer a suitable nutritional strategy to overcome the disadvantageous effects of HS in broiler production.
Acknowledgements. This work was financially supported by the University of Birjand, Iran.

Edited by: S. Maak

Reviewed by: two anonymous referees

\section{References}

Ahmad, T., Mushtaq, T., Mahr-Un-Nisa, Sarwar, M., Hooge, D. M., and Mirza, M. A.: Effect of different non-chloride sodium sources on the performance of heat-stressed broiler chickens, $\mathrm{Br}$. Poult. Sci., 47, 249-256, 2006.

Attia, Y. A., Al-Hanoun, A. M., and Bovera, F.: Effect of different levels of bee pollen on performance and blood profile of New Zealand White bucks and growth performance of their offspring during summer and winter months, J. Anim. Physiol. Anim. Nutr., 95, 17-26, 2011.

Bankova, V. S., Castro, S. L., and Marcucci, M. C.: Propolis: Recent advances in chemistry and plant origin, Apidologie., 31, 3-15, 2000.

Banskota, A. H., Tezuka, Y., Adnyana, I. K., Midorikawa, K., Matsushige, K., Message, D., Huertas, A. A., and Kadota, S.: Cytotoxic, hepatoprotective and free radical scavenging effects of propolis from Brazil, Peru, the Netherlands and China, J. Ethnopharmacol., 72, 239-246, 2000.

Bongiovanni, G. A., Soria, E. A., and Eynard, A. R.: Effects of the plant flavonoids silymarin and quercetin on arsenite-induced oxidative stress in CHO-K1 cells. Food Chem. Toxicol., 45, 971976, 2007.

Chiang, W., Booren, A., and Strasburg, G.: The effect of heat stress on thyroid hormone response and meat quality in turkeys of two genetic lines, Meat Sci., 80, 615-622, 2008.

Craig, E. A. and Gross, C. A.: Is HSP70 the cellular thermometer?, Trends Biochem. Sci., 16, 135-140, 1991.

Hu, C. H., Qian, Z. C., Song, J., Luan, Z. S., and Zuo, A. Y.: Effects of zinc oxide-montmorillonite hybrid on growth performance, intestinal structure, and function of broiler chicken, Poult. Sci., 92, 143-150, 2013.

Jacquier-Sarlin, M. R., Fuller, K., Dinh-Xuan, A. T., Richard, M. J., and Polla, B. S.: Protective effects of hsp70 in inflammation, Experiential, 50, 1031-1038, 1994.

Jia, G., Yan, J. Y., Cai, J. Y., and Wang, K. N.: Effects of encapsulated and non-encapsulated compound acidifiers on gastrointestinal $\mathrm{pH}$ and intestinal morphology and function in weaning piglets, J. Anim. Feed Sci., 19, 82-93, 2010.

Kamboh, A. A., Hang, S. Q., Bakhetgul, M., and Zhu, W. Y.: Effects of genistein and hesperidin on biomarkers of heat stress in broilers under persistent summer stress, Poult. Sci., 92, 2411-2418, 2013.

NRC: Nutrient requirements of poultry, National Academic Press, Washington, DC, USA, 19-34, 1994.

Patra, T., Pati, P. K., and Mohapatra, A. K.: Study on carcass quality of coloured broiler chicks supplemented with vitamin E and C during summer stress, SAARC J. Agric., 9, 123-132, 2011.

Quinteiro-Filho, W. M., Ribeiro, A., Ferraz-Depaula, V., Pinheiro, M. L., Saki, M., Sa, L. R., Ferreira, A. J., and Palermo-Neto, J.: Heat stress impairs performance parameters, induces intestinal injury, and decreases macrophage activity in broiler chickens, Poult. Sci., 89, 1905-1914, 2010. 
Quinteiro-Filho, W. M., Gomes, A. V. S., Pinheiro, M. L., Ribeiro, A., Ferraz-Depaula, V., Astolfi-Ferreira, C. S., Ferreira, A. J. P., and Palermo-Neto, J.: Heat stress impairs performance and induces intestinal inflammation in broiler chickens infected with Salmonella Enteritidis, Avian Pathol., 41, 421-427, 2012.

Rivera, L. R., Thacker, M., Pontell, L., Cho, H. J., and Furness, J. B.: Deleterious effects of intestinal ischemia/reperfusion injury in the mouse enteric nervous system are associated with protein nitrosylation, Cell Tissue Res., 344, 111-123, 2011.

SAS Institute: SAS/STAT Guide for personal computers, Version 9.1 Edition SAS Institute, Inc., Cary, NC, USA, 2006.

Seven, P. T.: The effects of dietary Turkish propolis and vitamin C on performance, digestibility, egg production and egg quality in laying hens under different environmental temperatures, AsianAustral. J. Anim. Sci., 21, 1164-1170, 2008.

Sohail, M. U., Hume M. E., Byrd J. A., Nisbet, D. J., Ijaz, A., Sohail, A., Shabbir, M. Z., and Rehman, H.: Effect of supplementation of prebiotic mannan-oligosaccharides and probiotic mixture on growth performance of broilers subjected to chronic heat stress, Poult. Sci., 91, 2235-2240, 2012.
Viuda-Martos, M., Ruiz-Navajas, Y., Fernández-López, J., and Pérez-Alvarez, J. A.: Functional properties of honey, propolis, and royaljelly, J. Food Sci., 73, 117-124, 2008.

Vleck, C. M., Vertalino, N., Vleck, D., and Bucher, T. L.: Stress, corticosterone and heterophil to lymphocyte ratios in free-living Adelie penguins, The Condor, 102, 392-400, 2000.

$\mathrm{Xu}, \mathrm{X}$., Sun, L., Dong, J., and Zhang, H.: Breaking the cells of rape bee pollen and consecutive extraction of functional oil with supercritical carbon oxide, Innov. Food Sci. Emerg. Technol., 10, 42-46, 2009.

Yahav, S., Shamay, A., Horev, G., Bar-Ilan, D., Genina, O., and Friedman-Einat, M.: Effect of acquisition of improved thermotolerance on the induction of heat shock proteins in broiler chickens, Poult. Sci., 76, 1428-1434, 1997. 